\title{
Antibiotic-prescribing patterns for Iraqi patients during Ramadan
}

\author{
This article was published in the following Dove Press journal: \\ Patient Preference and Adherence \\ 26 November 2014 \\ Number of times this article has been viewed
}

\author{
Ehab Mudher Mikhael \\ Ali Lateef Jasim \\ Clinical Pharmacy Department, \\ College of Pharmacy, Baghdad \\ University, Baghdad, Iraq
}

\begin{abstract}
Background: During Ramadan, Muslims fast throughout daylight hours. There is a direct link between fasting and increasing incidence of infections. Antibiotic usage for treatment of infections should be based on accurate diagnosis, with the correct dose and dosing regimen for the shortest period to avoid bacterial resistance. This study aimed to evaluate the practices of physicians in prescribing suitable antibiotics for fasting patients and the compliance of the patients in using such antibiotics at regular intervals.
\end{abstract}

Materials and methods: An observational study was carried out during the middle 10 days of Ramadan 2014 in two pharmacies at Baghdad. A total of 34 prescriptions ( $R x)$ for adults who suffered from infections were examined. For each included Rx, the researchers documented the age and sex of the patient, the diagnosis of the case, and the name of the given antibiotic(s) with dose and frequency of usage. A direct interview with the patient was also done, at which each patient was asked about fasting and if he/she would like to continue fasting during the remaining period of Ramadan. The patient was also asked if the physician asked him/her about fasting before writing the Rx.

Results: More than two-thirds of participating patients were fasting during Ramadan. Antibiotics were prescribed at a higher percentage by dentists and surgeons, for which a single antibiotic with a twice-daily regimen was the most commonly prescribed by physicians for patients during the Ramadan month.

Conclusion: Physicians fail to take patient fasting status into consideration when prescribing antibiotics for their fasting patients. Antibiotics with a twice-daily regimen are not suitable and best to be avoided for fasting patients in Iraq during Ramadan - especially if it occurs during summer months - to avoid treatment failure and provoking bacterial resistance.

Keywords: fasting, Ramadan, antibiotics, dosing regimen

\section{Introduction}

Ramadan is the most religious period of the Islamic calendar, during which millions of Muslims fast throughout the daylight hours. Drinking and eating are not permitted during daylight, and are allowed only at nightfall. The duration of daily fasting is influenced by seasonal and geographical conditions, which may vary from 11 to 18 hours per day. ${ }^{1}$ Although sick people are exempted from the duty of fasting, many Muslims may not perceive themselves as sick and are keen to fast. ${ }^{2}$ Many studies have shown a linkage between fasting and increasing incidence of infections. ${ }^{3,4}$ Moreover, antibiotics are one of the commonly prescribed drugs in the outpatient setting, ${ }^{5}$ so it is not surprising to find that antibiotics are commonly prescribed by outpatient physicians for fasting patients. Unfortunately, the probability of development and spread of antibiotic-resistant bacteria is increased whenever an antibiotic is used, whether appropriately or not, in human beings or even in animals. ${ }^{6}$ Many considerations may be taken into account with prescribing antimicrobial therapy to ensure patients benefit
Correspondence: Ehab Mudher Mikhae Clinical Pharmacy Department, College of Pharmacy, Baghdad University, Bab Almuatham, Baghdad, Iraq Tel +96477062l 6933

Email ehab_pharma84@yahoo.com
Patient Preference and Adherence 2014:8 1647-I65I

1647

Dovepress

http://dx.doi.org// 0.21 47/PPA.S7340/ (c) (i) (5) 2014 Mikhael and Jasim. This work is published by Dove Medical Press Limited, and licensed under Creative Commons Attribution - Non Commercial (unported, v3.0) permission from Dove Medical Press Limited, provided the work is properly attributed. Permissions beyond the scope of the License are administered by Dove Medical Press Limited. Information on permission Irom Dove Medical Press Limited, provided the work is properly attributed. P 
from the treatment without provoking bacterial resistance, eg, obtaining an accurate diagnosis of infection, understanding the difference between empiric and definitive therapy, identifying opportunities to switch to narrow-spectrum medication, and cost-effective oral agents for the shortest duration necessary. ${ }^{7}$ However, irrational antibiotic use is common in developing countries, which may be due to incorrect dose, frequency, or duration. ${ }^{8}$ The irrational use of antibiotics may result in a steady increase in antibiotic resistance. ${ }^{9,10}$ This study aimed to test the accuracy of antibiotic-dosing regimens in patients who were fasting according to the ritual rules of Ramadan in Iraq.

\section{Materials and methods}

This observational study was carried out during the middle 10 days of Ramadan 2014 in Baghdad, Iraq at two different free-standing pharmacies: one in Al-Amria (west of Baghdad) and the other in Al-Shaa'b (east of Baghdad). Ethical approval for this study was obtained from the ethical committee at Baghdad University College of Pharmacy.

All prescriptions $(\mathrm{Rx})$ that contained antibiotics for adult patients were included in the study. Thirty-seven prescriptions were involved in the study; however, three patients refused to mention their real age, and thus were excluded from this study.

For each $\mathrm{Rx}$, the researchers documented the age and sex of the patient, the diagnosis of the case, and the name of the given antibiotic(s) with dose and frequency of use. A direct interview with the patient in a quiet corner of the pharmacy was also done to ensure the privacy of each patient during the interview, and then each patient was asked about fasting and if he/she would like to continue fasting during the remaining period of Ramadan. The patient was also asked if the physician had asked him/her about fasting before the Rx was written.

Microsoft Excel 2007 was used for data input and analysis. Categorical variables are presented as numbers and percentages, while continuous variables are presented as means \pm standard deviation. The $\chi^{2}$ test (Internet-based calculator) was used to test the significance of difference for categorical variables. Pearson correlation was conducted to test the significance of correlation for categorical variables after their conversion into suitable continuous variables and according to the following: each fasting state was converted to 1 , while a nonfasting state was converted to 0 . Asking the patient about fasting by a physician was converted to 1 , while the absence of such a question was considered as 0 . For antibiotic-dosing regimens, each once-daily dosing
Table I Demographic data for the patients and prescriptions

\begin{tabular}{ll}
\hline Parameter & Value \\
\hline Age, years & $33.74 \pm 10.58$ \\
Sex, female/male & $23 / 1$ I \\
Fasting patients & $23(67.6 \%)$ \\
Number of Rx & 34 \\
Number of antibiotics prescribed & 44 \\
Number of Rx with one antibiotic & $24(70.6 \%)$ \\
Number of Rx with two antibiotics & $10(29.4 \%)$ \\
Number of Rx according to physician specialty & \\
Dentists & $12(35.3 \%)$ \\
Surgeons & $9(26.5 \%)$ \\
Gynecologists & $6(17.7 \%)$ \\
General practitioners & $3(8.8 \%)$ \\
Radiologists & $2(5.9 \%)$ \\
Urologists & $1(2.9 \%)$ \\
Dermatologists & $1(2.9 \%)$ \\
Pharmacological classification of prescribed antibiotics* & \\
Antiprotozoal (metronidazole) & $14(29.1 \%)$ \\
Aminoglycoside & $2(4.2 \%)$ \\
Cephalosporin & $13(27.1 \%)$ \\
Macrolide & $5(10.4 \%)$ \\
Penicillin & $5(10.4 \%)$ \\
Quinolone & $8(16.7 \%)$ \\
Tetracyclines & $1(2.1 \%)$ \\
\hline Notes: $*$ The actual number of prescribed antibiotics is higher than & 44 since some \\
antibiotic medications are combination of 2 antibiotics, like Rodogyl ${ }^{\otimes}$. Age was pres- \\
ented as mean plus minus standard deviation, while other parameters presented as \\
numbers (with some presented with numbers and percentages between brackets). \\
Abbreviation: Rx, prescriptions. & \\
&
\end{tabular}

was considered equal to 1 , twice daily equal to 2 and thrice daily equal to 3 . SPSS 12 was used for measuring Pearson correlation. $P$-values less than 0.05 were considered significant.

\section{Results}

Table 1 shows that 34 patients were included in this study; most of the participants were females, with an average age of 33.74 years. More than two-thirds of participants were fasting during Ramadan. Antibiotics were prescribed at a higher percentage by dentists and surgeons. The majority $(70.6 \%)$ of prescriptions included one antibiotic. Metronidazole and

Table 2 Patients' fasting status according to disease etiology

\begin{tabular}{lll}
\hline Disease & Fasting & Nonfasting \\
\hline $\begin{array}{l}\text { Dental infections and } \\
\text { dental procedure prophylaxis }\end{array}$ & $7(58.3 \%)$ & $5(41.7 \%)$ \\
GIT infections & $3(60 \%)$ & $2(40 \%)$ \\
UTIs and renal stones & $8(66.7 \%)$ & $4(33.3 \%)$ \\
Gynecological infections & I (100\%) & 0 \\
Dermatological infections & I (I00\%) & 0 \\
Others (like wound and surgical & $3(100 \%)$ & 0 \\
prophylaxis) & & \\
\hline
\end{tabular}

Abbreviations: GIT, gastrointestinal tract; UTIs, urinary tract infections. 
Table 3 Relationship between fasting and number of Rx antibiotics

\begin{tabular}{lllll}
\hline $\begin{array}{l}\text { Number of } \\
\text { antibiotics in Rx }\end{array}$ & $\begin{array}{l}\text { Frequency of } \\
\text { antibiotic usage }\end{array}$ & $\begin{array}{l}\text { Patient asked about } \\
\text { fasting by the physician }\end{array}$ & Fasting & Nonfasting \\
\hline Single antibiotic & Once & $7(87.5 \%)$ & $6(75 \%)$ & $2(25 \%)$ \\
& Twice & $10(66.7 \%)$ & $10(66.7 \%)$ & $5(33.3 \%)$ \\
& Thrice & $1(100 \%)$ & $1(100 \%)$ & 0 \\
Double antibiotics & Once & $2(100 \%)$ & $2(100 \%)$ & 0 \\
& Twice & $3(100 \%)$ & $3(100 \%)$ & $2(40 \%)$ \\
\hline
\end{tabular}

Abbreviation: $\mathrm{Rx}$, prescriptions.

cephalosporins were the most common types of antibiotics that were prescribed for patients during Ramadan.

Table 2 shows that dental infections and procedures like tooth extraction were the most common causes for Iraqi patients to stop fasting. Tables 3 and 4 show that the majority of patients during Ramadan were prescribed antibiotics with a twice-daily regimen. There was no statistical difference between the antibiotic-dosing regimens prescribed for fasting and nonfasting patients. In contrast to what was expected, the percentage of patients who were prescribed antibiotics with thrice daily regimen was higher among fasting patients than those in the non fasting state. Furthermore, physicians were less likely to ask the patient about fasting status when they prescribed two antibiotics with a thrice-daily regimen.

Table 5 shows that a single antibiotic was prescribed more frequently in fasting patients, whereas in prescribing dual antibiotics there was an insignificant difference between fasting and nonfasting patients. Table 6 shows that there was no correlation between physician questioning about fasting and number or dosing regimen of antibiotics prescribed, but there was a significant positive correlation with the actual fasting status of the patient.

Table 7 shows a number of antibiotics that were prescribed in a modified dosing regimen in order to ensure patient compliance during Ramadan. Metronidazole was prescribed twice daily in three cases; one of them was for a patient who was not fasting. Gentamicin was given once daily in a fasting patient, but unfortunately the dose was too small and insufficient to be considered as a shooting dose.

Table 4 Antibiotic-dosing regimen according to fasting status of the patient

\begin{tabular}{llll}
\hline Parameter & \multicolumn{3}{l}{ Antibiotic-dosing regimen } \\
\cline { 2 - 4 } & Once daily & Twice daily & Thrice daily \\
\hline Fasting & $3(13.04 \%)$ & II $(47.82 \%)$ & $9(39.14 \%)$ \\
Nonfasting & $3(27.27 \%)$ & $6(54.55 \%)$ & $2(18.18 \%)$ \\
P-value & 0.3 & 0.7 & 0.22 \\
\hline
\end{tabular}

\section{Discussion}

This study showed that more than two-thirds of participating patients were fasting during Ramadan. Similarly, other studies have shown that most patients in Arabic countries still fast despite their illness. ${ }^{11,12}$ Antibiotics were prescribed at a higher percentage by dentists. It has been found that dentists are among the top five specialists that prescribe antibiotics in the world. ${ }^{13}$

This study demonstrated that the majority of prescriptions included one antibiotic, since the need for multiple antibiotics is necessary only in limited cases, such as in severe or complicated infections. ${ }^{7}$ Additionally, most patients suffering from infections during Ramadan were prescribed metronidazole and/or cephalosporins. There are many reasons to prescribe cephalosporins frequently, such as lower allergenic and toxicity risks, as well as their broad spectrum of activity, ${ }^{14}$ while the popularity of metronidazole may be related to its multiple actions on different microorganisms like protozoa and anaerobes. ${ }^{15}$

This study also showed that dental infections and procedures like tooth extraction were the most common reasons to stop fasting among Iraqi patients. This result could be explained in that toothache is severe and the patient needs to use some analgesics, ${ }^{16}$ which are better to be taken after a meal to prevent their gastrointestinal side effects, ${ }^{17}$ which in turn means that the patient is required to eat. Therefore, it is very difficult for the patient to continue with his/her fasting.

The results of this study revealed that a single antibiotic with a twice-daily regimen was the most commonly prescribed treatment for fasting patients during Ramadan. This

Table 5 Single versus double antibiotics prescribing according to fasting status of the patient

\begin{tabular}{lll}
\hline Parameter & \multicolumn{2}{l}{ Number of antibiotics used } \\
\cline { 2 - 3 } & Single & Double \\
\hline Fasting & 17 & 8 \\
Nonfasting & 7 & 2 \\
$P$-value & $0.04 \mathrm{I}$ & 0.057 \\
\hline
\end{tabular}


Table 6 Correlation between the physician questioning the patient about fasting and other parameters

\begin{tabular}{lll}
\hline Parameter & Correlation coefficient & $P$-value \\
\hline Antibiotics prescribed & 0.054 & 0.763 \\
Frequency of use per day & -0.218 & 0.215 \\
Fasting status of the patient & 0.506 & 0.002 \\
\hline
\end{tabular}

pattern may be used to ensure patient compliance, since compliance decreases with increasing complexity of the regimen. ${ }^{18}$ Furthermore, it has been found that there was no significant difference between patient compliance with oncedaily and twice-daily regimens. ${ }^{18,19}$ However, these studies were carried out in nonfasting individuals, while in this study fasting patients who wished to continue their fasting were subjected to very long fasting periods, which exceed 16 hours in Iraq, so that patients were unable to use their antibiotic on a regular basis every 12 hours. Similarly, it was found that the majority of patients changed their drug-intake pattern, specifically changing their drug regimens during Ramadan..$^{20,21}$ In addition, the results of this study showed that there was no statistical difference between the antibiotic-dosing regimen prescribed for fasting and nonfasting patients, yet there was a significant preference by physicians to prescribe a single antibiotic to fasting patients. This means that although physicians tried to ensure patient compliance with the prescribed antibiotic by respecting patient wishes to continue their fasting, they failed to choose an antibiotic with a suitable dosing regimen. This failure may occur because of lack of sufficient pharmacological knowledge by the physicians about the drug facts and lack of sufficient time to discuss such problems with their patients. Therefore, this means that even patients who complied with the use of the prescribed antibiotic just prior to and after the fast, there was an unintentional lack of adherence by patients with the correct twice-daily dosing that should ensure 12-hour intervals between doses. The failure to use antibiotics on the correct dosing regimen may ultimately result in treatment failure and increase the chance for bacterial resistance. ${ }^{22,23}$ Therefore, the prescribed antibiotics with a twice-daily regimen for fasting patients in Iraq were not suitable and best to be avoided.

The results of this study also showed another problem with the prescribing patterns of physicians to fasting patients.

Table 7 Antibiotics prescribed in a modified dosing regimen

\begin{tabular}{lllll}
\hline Antibiotic & $\begin{array}{l}\text { Dosing } \\
\text { regimen }\end{array}$ & $\begin{array}{l}\text { Number } \\
\text { of cases }\end{array}$ & $\begin{array}{l}\text { Fasting } \\
\text { status }\end{array}$ & $\begin{array}{l}\text { Physician asked } \\
\text { about fasting }\end{array}$ \\
\hline Metronidazole & $\begin{array}{l}\text { Twice daily } \\
\text { Gentamicin }\end{array}$ & 3 & 2 & 3 \\
Once daily & $\mathrm{I}$ & $\mathrm{I}$ & $\mathrm{I}$ \\
\hline
\end{tabular}

Physicians were less likely to ask the patient about fasting status when they prescribed two antibiotics with a thrice-daily regimen. This may have been due to physicians not having sufficient time to ask their patients about fasting. They might also have been more confident in using certain type of antibiotics especially those with thrice daily regimen, at which they were sure that the dosing regimen of these antibiotics can't be used accurately in fasting patients, and the patient to get benefit from his/her treatment must stop fasting. This in turn may have been taken by some patients as disrespectful behavior toward their autonomy and dignity, and could have resulted in damaging the relationship between the patient and the physician, which could have led to patient noncompliance and bad adherence to his/her medications. This finding occurs in concordance with the absence of any correlation between questioning by the physician about fasting and the number or dosing regimen of antibiotics prescribed. This means that even if physicians ask about fasting, this question does not change his/her prescribing pattern according to patient preference and fasting status.

This study showed that physicians are trying to modify antibiotic-dosing regimens for patients to enhance their compliance. Since it is well known that a shooting dose of gentamicin is not only less toxic but also ensures more compliance by the patient, but higher than usual doses of gentamicin are required by shooting doses, and the use of low doses can result in treatment failure and the provoking of bacterial resistance. ${ }^{24}$

Although this study examined for the first time antibioticdosing regimens for fasting patients, it has many limitations, eg, small sample size and absence of patient follow-up to detect actual adherence and compliance to the prescribed antibiotic and to detect the response to such therapy, as shown by clinically and laboratory-evidenced resolution of infectious symptoms. Further and larger studies with sufficient follow-up periods are necessary to confirm the findings of this study.

In conclusion, the twice-daily regimen is the preferred regimen by most physicians in treating the infections of patients; however, antibiotics with twice-daily regimens are not suitable for fasting patients, even if they had been compliant with taking the drug twice daily just prior to and just after the fast, since this way of taking the medication is not sufficient to ensure 12-hour intervals and is thus best to be avoided to prevent the provoking of bacterial resistance and treatment failure for fasting patients in Iraq during Ramadan, especially if it occurs during the summer months, in which more than 16 hours of fasting per day is mandatory. In other 
words, physicians failed to take patient fasting status into consideration when prescribing antibiotics.

\section{Disclosure}

The authors report no conflicts of interest in this work.

\section{References}

1. Azizi F. Research in Islamic fasting and health. Ann Saudi Med. 2002;22(3-4):186-191.

2. Chamsi-Pasha H, Albar MA. Fasting Ramadan from Islamic and Medical Perspective. Jeddah: Al-Dar Al-Saudia; 2005.

3. Bandyopadhyay S, Thakur JS, Ray P, Kumar R. High prevalence of bacteriuria in pregnancy and its screening methods in north India. J Indian Med Assoc. 2005;103(5):259-262, 266.

4. Bragazzi NL. Ramadan fasting and infectious diseases. In: Chtourou H, editor. Effects of Ramadan Fasting on Health and Athletic Performance. Hyderabad: OMICS; 2014.

5. Irshaid YM, Al-Homrany MA, Hamdi AA, Adjepon-Yamoah KK, Mahfouz AA. A pharmacoepidemiological study of prescription pattern in outpatient clinics in southwestern Saudi Arabia. Saudi Med J. 2004; 25(12):1864-1870.

6. Austin DJ, Kristinsson KG, Anderson RM. The relationship between the volume of antimicrobial consumption in human communities and the frequency of resistance. Proc Natl Acad Sci U S A. 1999;96(3): 1152-1156.

7. Leekha S, Terrell CL, Edson RS. General principles of antimicrobial therapy. Mayo Clin Proc. 2011;86(2):156-167.

8. Ganguly NK1, Arora NK, Chandy SJ, et al. Rationalizing antibiotic use to limit antibiotic resistance in India. Indian J Med Res. 2011;134(3): 281-294.

9. Radyowijati A, Haak H. Improving antibiotic use in low-income countries: an overview of evidence on determinants. Soc Sci Med. 2003; 57(4):733-744.

10. Islam MS, Islam MA, Khondkar P. Isolation and in vitro antibiotic resistance and susceptibility pattern of a strain of E. coli. Bangladesh Pharm J. 2010;13(1):34-37.
11. Chamsi-Pasha H, Aljabri KS. The diabetic patient in Ramadan. Avicenna J Med. 2014;4(2):29-33.

12. Mohamed M, NasrAllah and Noha A, Osman. Fasting during the month of Ramadan among patients with chronic kidney disease: renal and cardiovascular outcomes. Clin Kidney J. 2014;0:1-6.

13. Hicks LA, Taylor TH Jr, Hunkler RJ. U.S. outpatient antibiotic prescribing, 2010. N Engl J Med. 2013;368(15):1461-1462.

14. Dancer SJ. The problem with cephalosporins. J Antimicrob Chemother. 2001;48(4):463-478.

15. Löfmark S, Edlund C, Nord CE. Metronidazole is still the drug of choice for treatment of anaerobic infections. Clin Infect Dis. 2010;50 Suppl 1: S16-S23.

16. Cohen LA, Harris SL, Bonito AJ, et al. Coping with toothache pain: a qualitative study of low-income persons and minorities. J Public Health Dent. 2007;67(1):28-35.

17. Rainsford KD, Bjarnason I. NSAIDs: take with food or after fasting? J Pharm Pharmacol. 2012;64(4):465-469.

18. Claxton AJ, Cramer J, Pierce C. A systematic review of the association between dose regimens and medication compliance. Clin Ther. 2001; 23(8):1296-1310.

19. Greenberg RN. Overview of patient compliance with medication dosing: a literature review. Clin Ther. 1984;6(5):592-599.

20. Aslam M, Healy MA. Compliance and drug therapy in fasting Moslem patients. J Clin Hosp Pharm. 1986;11(5):321-325.

21. Aslam M, Assad A. Drug regimens and fasting during Ramadan: a survey in Kuwait. Public Health. 1986;100(1):49-53.

22. Roberts JA, Kruger P, Paterson DL, Lipman J. Antibiotic resistance - what's dosing got to do with it? Crit Care Med. 2008;36(8): 2433-2440.

23. Martin LR, Williams SL, Haskard KB, Dimatteo MR. The challenge of patient adherence. Ther Clin Risk Manag. 2005;1(3):189-199.

24. Labovitz E, Levison ME, Kaye D. Single-dose daily gentamicin therapy in urinary tract infection. Antimicrob Agents Chemother. 1974;6(4): $465-470$.
Patient Preference and Adherence

\section{Publish your work in this journal}

Patient Preference and Adherence is an international, peer-reviewed, open access journal that focuses on the growing importance of patient preference and adherence throughout the therapeutic continuum. Patient satisfaction, acceptability, quality of life, compliance, persistence and their role in developing new therapeutic modalities and compounds to optimize

\section{Dovepress}

clinical outcomes for existing disease states are major areas of interest for the journal. This journal has been accepted for indexing on PubMed Central. The manuscript management system is completely online and includes a very quick and fair peer-review system, which is all easy to use. Visit http://www. dovepress.com/testimonials.php to read real quotes from published authors. 